\title{
Treatment of Post-Burn Scars of the Face by Er: YAG Laser
}

\author{
ABDEL RAHMAN ASFOUR, M.Sc.*; HISHAM A. SHOKAIR, M.D.**; TAREK F. EL-WAKIL, M.D.**; \\ FOUAD GHAREEB, F.R.C.S., M.D.*** and MAHMOUD S. EL-BASIOUNY, M.D.** \\ Maadi Plastic Surgery Center*, Cairo, Medical Applications of Laseres Department**, National Institute of Laser \\ Enhanced Sciences, Cairo University and Department of Plastic Surgery***, Faculty of Medicine, Menofia University, \\ Menofia Governorate, Egypt
}

\begin{abstract}
Aim: To determine the effects of Er:YAG laser in the management of facial post-burn scars by ablative and fractional lasers.

Background: Post burn scars of the face can be hypertrophic, atrophic, keloid, hyper pigmented or hypo pigmented scars, Erbium-Yag laser was documented to treat these scars effectively.

Patients and Methods: 15 patients with facial post-burn scars were treated by Er:YAG laser. The lower $3^{\text {rd }}$ is affected in $70 \%$ of the cases, middle $3^{\text {rd }}$ is affected in $20 \%$ and upper $3^{\text {rd }}$ is affected in $10 \%$ of the cases. Fractional mode was used for 9 patients with pigmentation and vascularity, and 6 patients was treated by ablative mode for height and pliability.

Results: The patients were assessed clinically by Vancouver scar assessment scale (VSS) as regard pliability, height, vascularity and hyperpigmentation and assessed histopathologically by hematoxyline-eosin (H\&E) and Masson's Trichrome. The $1^{\text {st }}$ group shows improvement in pigmentation by VSS assessment in $66.7 \%$ and hypevascularity in $60.0 \%$ of the patients, while in the second group improvement occurred in height in $86.7 \%$ and pliability in $80.0 \%$ of the patients.
\end{abstract}

Conclusion: Ablative and fractional modes of laser Er: YAG can be used for treatment of facial post-burn hypertrophic scars with good results.

Key Words: Lasers - Burn scar - Er: YAG: Ablative - Fractional modes.

\section{INTRODUCTION}

Post-burn scars have functional and cosmetic influences on affected individuals due to their aberrant wound healing [1]. A healed burn patient may be left with scars and disfigurement which have down effects on self esteem, body image and overall quality of life [2,3]. Burn scars have, in addition, some functional morbidity such as contractures, hypertrophic changes and keloid formation. Furthermore, burn scars could produce persistent hyperemia, chronic folliculitis, intense and unrelenting pruritus and neuropathic pain $[4,5]$.
Burn scars are either hypertrophic, atrophic or keloids; with a number of symptoms and functional deficits. Determining the type of scarring and the associated symptoms is important to decide the type of therapy needed treatment of burn scars is challenging and difficult despite the many options available including pressure therapy, silicone gel, intralesional or topical corticosteroids, radiation and interferon [6]. There have been advocates for scar excision, this is usually followed by primary closure, with or without tissue expansion or with flaps or grafts. These therapies have high failure and recurrence rates, as well as significant side effects [7].

For more than 25 years, laser therapy has been used for the treatment of scars; in the medical literature there are different laser- and light-based technologies that are poised to dramatically alter our reconstructive algorithm and create a major paradigm shift in the management of burn scars. These are vascular-specific pulsed dye laser (PDL), ablative/non ablative fractional laser resurfacing. Intense pulsed light (IPL) and some other laser types $[8,9]$.

PDL demonstrated an improvement in burn scar texture, pliability, erythema, pruritis, pain and reduction in scar volume (34-66\% improvement) [10].

IPL showed improvement in terms of scar height, erythema and hardness with a moderate level of patient satisfactional though there is lack of evidence for its efficacy [11].

Although the mechanism of action for scar improvements is unknown, most theories are based on the principle that vascular proliferation plays a key role in scar so dye laser and light based therapies could be effective in fresh scars. Mature 
scars with aberrant collagen deposition are treated with resurfacing. Laser resurfacing is a technique that is commonly accomplished via ablative devices such as conventional carbon dioxide laser, that provides the greatest improvement with a single treatment, but significant adverse effects limit its use and patient downtime can be extensive [12].

Er: YAG lasers, with wave lengths of $2940 \mathrm{~nm}$, are 10 times more selective for water than $\mathrm{CO} 2$, laser it penetrates to an average depth of $2-5 \mathrm{~nm}$ per $\mathrm{J} / \mathrm{cm}^{2}$ and the necrotic layer is completely removed during each new pass, and even after multiple passes, the residual necrotic layer does not exceed 10-15 $\mu \mathrm{m}$. Er: YAG laser is effective in resurfacing skin with fine and superficial atrophic scars, yielding similar results to that of $\mathrm{CO}_{2}$ laser, Er: YAG re-epitheliaization typically takes 4-7 days so it decreases post-operative erythema and recovery times $[\mathbf{1 3}, \mathbf{1 4}]$.

Fractional laser are gaining popularity and have been successfully utilized in the treatment of scars; because fractional resurfacing treating $20 \%, 40 \%$ or $90 \%$ of the area this could provide rapid reepitheliaization which consider this treatment highly effective with significant low risk of complications [15].

While normal skin will re-epithelialize quickly and evenly from hair follicles and dermal glands after dermabrasion or laser ablation, burn scars are often partially or completely deprived of their epidermal appendages so during resurfacing of such scars, it is advisable to save spots of intact epidermal basal layer, which can serve as islands for re-epitheliaization [16].

As the Erbium: YAG laser provides ideal options to maintain such re-epitheliaization procedure.

The aim of this study was to prospectively evaluate the efficacy and safety of a $2940 \mathrm{~nm}$ Er: YAG laser whether in its ablative/fractional modes in the treatment of post burn hypertrophic scars.

\section{PATIENTS AND METHODS}

This was a prospective study, from both a clinical and histological perspective aspects to study the effect of Er: YAG laser on patients with mature bum scars. The study was conducted in outpatient clinic at the National Institute of Laser Enhanced Sciences, Cairo University, between December 2011 to May 2014. The present study was conducted on 15 patients divided into two groups, group I-treated with ablative Er: YAG laser mode and group II-treated with Fractional Er: YAG laser modes patient, Gender distribution between groups showed 6 males and 9 females at different age groups. The study included mature and stable post burn hypertrophic scars of at least one year duration of different shapes and surface areas and different body locations of the face, this study approved by ethical committee, all subjects provided written informed consents. Patients with keloids tendency. Photosensitivity, below 5 years old or on oral retinoids within the last 6 months were excluded from the study. The included patients were randomly divided into 2 equal treatment groups: Group I: Included 9 patients subjected to ablative Er: YAG laser. Group II: Included 6 patients subjected to fractional Er: YAG laser.

\section{Laser system:}

The laser used in this study was Er: YAG laser (XS dynamics FotonaS1-121d Ljubljana Slovenia) with following specifications $2940 \mathrm{~nm}$ and energy $3 \mathrm{~J}$, pulse duration $(100 \mu \mathrm{s}, 300 \mu \mathrm{s}, 600 \mu \mathrm{s}, 1500 \mu \mathrm{s}$ and $250 \mathrm{~ms}$ ). (Short Pulse: 300 microsecond) SP Mode does not allow heat to be transferred into the tissue and is used when strong ablation is required and flounce range up to $380 \mathrm{~J} / \mathrm{cmP} 2 \mathrm{P}$.

\section{Technique of ablative mode:}

For ablative mode the R11 hand piece was used this, straight hand piece has a variable spot sizes from 2 to $7 \mathrm{~mm}$. The R1 1 hand piece was used in a freehand method. The single spots were placed slightly overlapping in circles or any other pattern on the skin, while a constant spot overlapping of $30-40 \%$ was maintained. For an even subtotal de epithelialization of larger areas, we applied two passes at energy of $500-1000 \mathrm{~mJ}$ as provided by $5 \mathrm{~mm}$ spot size, an SP mode and $30-40 \%$ spot overlap.

In larger scar areas containing multiple prominent bands and lines, the elevations were first cleared away selectively using high power. In a second step, the whole scar area was sub totally de epithelialized using the above described energy mode in order to obtain an even regeneration and optical blending. On the face, complete aesthetical subunits were treated whenever possible.

\section{Technique for the fractional mode:}

The RO4 hand piece offers a unique fractional Er: YAG treatment modality. The RO4 is a variable hand piece that allows the number and size of pixel, as well as the overall spot size, to be varied. The hand piece can be set to provide 7, 10 and $12 \mathrm{~mm}$ treatment spot sizes and Pixel Size 20$300 \mu \mathrm{m}$. Number of Pixel 4-256 Pixels according to the selected level in larger scar areas the tech- 
nique we did, the first pass on all the area and the second pass only epitheliaization [16]. As the Erbium: YAG laser provides ideal options to maintain such re-epitheliaization procedure.

The aim of this study was to prospectively evaluate the efficacy and safety of a 2940nm Er; YAG laser whether in its ablative/fractional modes in the treatment of post burn hypertrophic scars.

On the elevated bands the average number of passes (3-5), Energy (1000-1200mJ) Mode SP, Spot size $(7 \mathrm{~mm})$ and frequency $(3-5 \mathrm{~Hz})$. The laser settings were developed from clinical experience with prior scar and resurfacing treatments. Adjustments were made within the described parameters for patient comfort.

\section{Treatment methods:}

Patients were treated in the outpatient clinics of Maadi Plastic Surgery Center, treatment was carried out using a topical anesthetic cream [EMIA (eutectic mixture of lidocaine and prilocaine) AstraZeneca, London, UK] applied to the scar area under occlusion 2 hours before treatment. Immediate follow-up examinations were prefunded after each session. To evaluate skin improvement, photographs were taken with a digital camera (HS movie 720 p, 12.1 megapixels resolution, Sony, Tokyo, Japan) before treatment and at each followup visit.

\section{Postoperative care:}

Wound care after laser treatment included a topical antibiotic ointment for several days, and return to work within 1 to 3 days. Postoperative analgesia was accomplished with non steroidal anti-inflammatory agents (NSAIDs).

\section{Patient assessments:}

Further follow-up was performed 7 and 30 days post treatment to monitor recovery, improvement and any subsequent squeal. Textural scar irregularity was also evaluated by the physician at these time points. The photographs taken before initiation of treatment and 3 months following the end of treatment were independently evaluated and compared.

Side effects and complications were recorded. Before start of treatment all subjects provided written informed consent clinical assessment was done before treatment and 6 months after the final treatment, assessment was done using the most widely used assessment scale Vancouver Scar (VSS), which measures vascularity, pliability, pigmentation and height giving a range of $0-14$ in the total score. It was originally designed to rate burn scars as follows vascularity $(0=$ normal, $1=$ pink, $2=$ red, $3=$ purple), pliability (Normal $=0$, Flat $=0$, Supple $=1$, Yielding $=2$, Firm $=3$, Ropes $=4$, Contracture $=5)$, Pigmentation $(0=$ normal, $1=$ hypopigmentation, $2=$ mixed pigmentation, $3=$ hyperpigmentation) and height (Flat $=0<2 \mathrm{~mm}=12-5$ $\mathrm{mm}=2>5 \mathrm{~mm}=2$ ).

\section{Histological assessment:}

The biopsy specimens were collected from scars treatment starts, the area of scar that was biopsied was carefully marked and photographed to ensure having die post treatment biopsy specimens taken adjacent to the pre-treatment biopsy. Punch biopsies $3 \mathrm{~mm}$ were performed on the treated area and sent for tissue processing and staining.

Tissue blocks were fixed in $10 \%$ buffered formalin, embedded in paraffin and sectioned in standard fashion. The stains included hematoxylin-eosin (H\&E) and Masson's Trichrome.

The clinical assessment of the scars face revealed that most scars had increased pigmentation compared with surrounding non involved skin. Hypertrophy was noted in some treatment areas. Immediately after treatment, the skin surface displayed a white-gray frost, which on close inspection revealed a pinpoint pattern corresponding to fractional laser dots. Assessment before each session after month of procedure and then every month revealed complete healing within 10-12 days and the scar surface was smooth and has soft texture (Figs. 1-6).

The obtained results showed that data were differed in pre and post treatment within each group however between the two groups the results showed dramatic differences for traditional ablative Er: YAG laser treatment over fractional Er: YAG laser treatment group the obtained results were for traditional ablative Er: YAG laser, the descriptive data results. Expressed revealed that for assessment results for pre and post treatment, respectively. The obtained results revealed high significant differences between pre and post treatment. For fractional Er: YAG laser.

\section{Histopathology:}

Pre-treatment histopathology of burn scar samples stained with H\&E.

The epidermis was characterized by flattening of the rete ridges, hyperkeratosis, hypergranulosis and regular palisading basal cell layer, blood vessels were oriented vertically. 
The dermis showed nodules composed of aggregates of fibroblasts, small vessels, thicker and stretched collagen bundles were seen throughout the dermis. A low-grade inflammation in tire dermis in the form of lymphocytes around telangiectatic vessels was found.

In Masson's trichrome stained samples replacement of papillary dermis with abnormal hyperplastic thicker collagen bundles was noticed and the peripheral layers of collagen forming a septal-like capsule.

a- The epidermis showed improved appearance after Er: YAG laser as the keratinocytes become well organized and malpighian layer thickness had increased together with thinning in the stratum corneum

b- The dermis showed a remarkable histological finding as cellular infiltrates was found in the upper dermis with increased number of fibroblasts and increased dermal vascularity. Masson's Trichrome stain revealed well-organized collagen bundles in the papillary dermis parallel to the epidermis with compact appearance, the only difference between samples after ablative and after fractional laser is that the ablative laser samples showed more parallel and dense collagen, bundles also a horizontal oriented fibrillar collagen. There was evident neocollagen formation in both samples.

\section{Statistical analysis of the data:}

Data were fed to the computer and analyzed using IBM SPSS software package version 20.0. Data were fed to the computer and analyzed using IBM SPSS software package version 20.0. (Armonk, NY: IBM Corp). Comparisons between groups for categorical variables were assessed using Chi-square test (Fisher or Monte Carlo). Significance of the obtained results was judged at the $5 \%$ level.

\section{RESULTS}

The age of our studied group ranged from 9 to 42 in males $(n=9)$ and from 11 to 64 in females $(n=6)$. The mean age was $25.89 \pm 9.80$ and $28.17 \pm$ 18.90 in males and females respectively. While the median age was 28.0 and 24.50 in males and females respectively. So there were no significant difference between males and females $(p=0.763)$ (Table 1).

\section{Scare site:}

The upper third face scar were found in one male $(11.1 \%)$ and one female $(16.7 \%)$ males $(33.3 \%)$ and one female $(16.7 \%)$. While the middle third scars were found in 3 five male patients had lower third scars $(55.6 \%)$ but only four females had a lower third scar $(66.7 \%)$. There were no relation between gender and scar site as showed in (Table 2).

\section{Skin type:}

Five males had skin type III (55.6\%) while only two females had type III skin $(33.3 \%)$. Four males $(44.4 \%)$ and four females $(66.7 \%)$ had type IV skin there is no relation between gender and skin type shows in (Table 3 ).

Table (1): Relation between gender and age $(n=15)$.

\begin{tabular}{|c|c|c|c|c|c|c|}
\hline & \multicolumn{4}{|c|}{ Gender } & \multirow{2}{*}{$t$} & \multirow{2}{*}{$p$} \\
\hline & \multicolumn{2}{|c|}{ Male $(n=9)$} & \multicolumn{2}{|c|}{ Female $(n=6)$} & & \\
\hline $\begin{array}{l}\text { Age (years): } \\
\text { Min.-Max. } \\
\text { Mean } \pm \text { SD } \\
\text { Median }\end{array}$ & \multicolumn{2}{|c|}{$\begin{array}{l}9.0-42.0 \\
25.89 \pm 9.80 \\
28.0\end{array}$} & $\begin{array}{l}11.0-64 \\
28.17 \pm 1 \\
24.50\end{array}$ & $\begin{array}{l}0 \\
8.90\end{array}$ & 0.308 & 0.763 \\
\hline \multicolumn{7}{|c|}{$\begin{array}{l}t \text { : Student } t \text {-test. } \\
p: p \text {-value for comparing between the two categories. }\end{array}$} \\
\hline \multicolumn{7}{|c|}{ Table (2): Relation between gender and s } \\
\hline & \multicolumn{4}{|c|}{ Gender } & \multirow{3}{*}{$\chi^{2}$} & \multirow{3}{*}{$\mathrm{MC}_{p}$} \\
\hline & \multicolumn{2}{|c|}{ Male $(\mathrm{n}=9)$} & \multicolumn{2}{|c|}{ Female $(\mathrm{n}=6)$} & & \\
\hline & No. & $\%$ & No. & $\%$ & & \\
\hline \multicolumn{7}{|c|}{ Scar site of face: } \\
\hline Upper $1 / 3$ & 1 & 11.1 & 1 & 16.7 & & \\
\hline Middle 1/3 & 3 & 33.3 & 1 & 16.7 & 0.815 & 1.000 \\
\hline Lower $1 / 3$ & 5 & 55.6 & 4 & 66.7 & & \\
\hline
\end{tabular}

Table (3): Relation between gender and skin types $(n=15)$.

\begin{tabular}{|c|c|c|c|c|c|c|}
\hline & \multicolumn{4}{|c|}{ Gender } & \multirow{3}{*}{$\chi^{2}$} & \multirow{3}{*}{$\mathrm{FE}_{p}$} \\
\hline & \multicolumn{2}{|c|}{ Male $(\mathrm{n}=9)$} & \multicolumn{2}{|c|}{ Female $(n=6)$} & & \\
\hline & No. & $\%$ & No. & $\%$ & & \\
\hline \multicolumn{7}{|l|}{ Skin types: } \\
\hline III & 5 & 55.6 & 2 & 33.3 & 0.714 & 0.608 \\
\hline IV & 4 & 44.4 & 4 & 66.7 & & \\
\hline
\end{tabular}

Table (4): Comparison between the two studied groups according to improvement in different parameters.

\begin{tabular}{|c|c|c|c|c|c|c|}
\hline & \multicolumn{2}{|c|}{$\begin{array}{l}\text { Ablative } \\
(\mathrm{n}=15)\end{array}$} & \multicolumn{2}{|c|}{$\begin{array}{l}\text { Fractional } \\
\quad(n=15)\end{array}$} & \multirow{2}{*}{$\chi^{2}$} & \multirow{2}{*}{$\mathrm{FE}_{p}$} \\
\hline & No. & $\%$ & No. & $\%$ & & \\
\hline Pigmentation & 10 & 66.7 & 13 & 86.7 & 1.677 & 0.390 \\
\hline Vascularity & 9 & 60.0 & 12 & 80.0 & 1.429 & 0.427 \\
\hline Highest & 13 & 86.7 & 9 & 60.0 & 2.727 & 0.215 \\
\hline Pal ability & 12 & 80.0 & 10 & 66.7 & 0.682 & 0.682 \\
\hline
\end{tabular}

FE: Fisher Exact. $\quad \chi^{2}$ : Chi square test. $p$ : $p$-value for comparing between the two groups. 


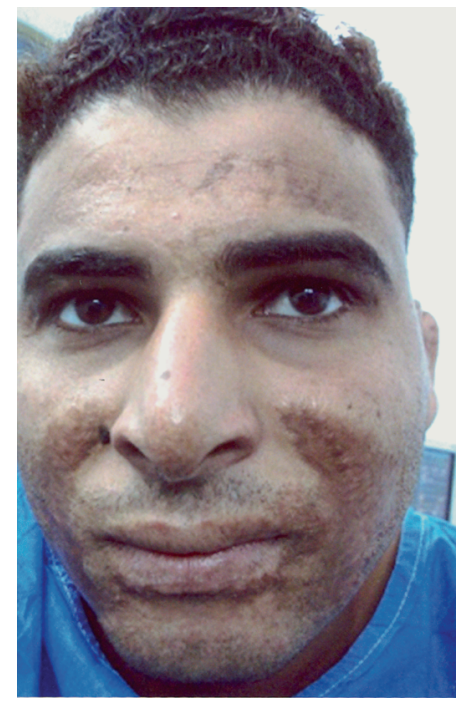

Fig. (1-A): Male pt 36ys old with post burn scar forehead \& cheek.

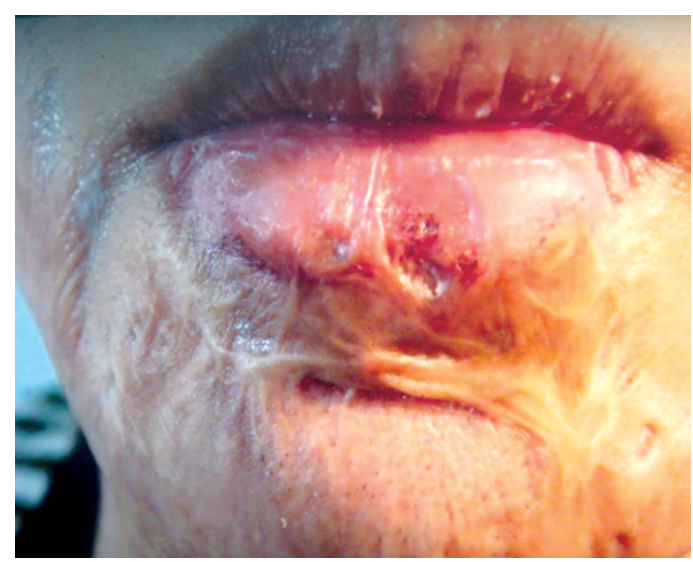

Fig. (2-A): Female pt 32ys old of post burn scar in chin.

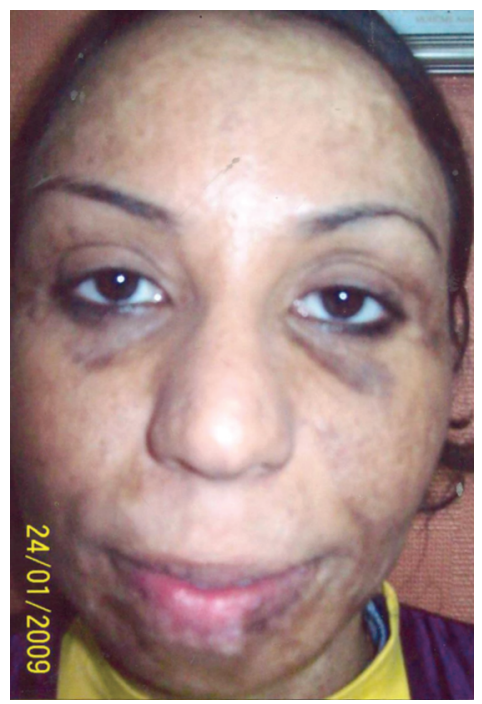

Fig. (3-A): Female pt 45ys old with post burn scar in lower lip

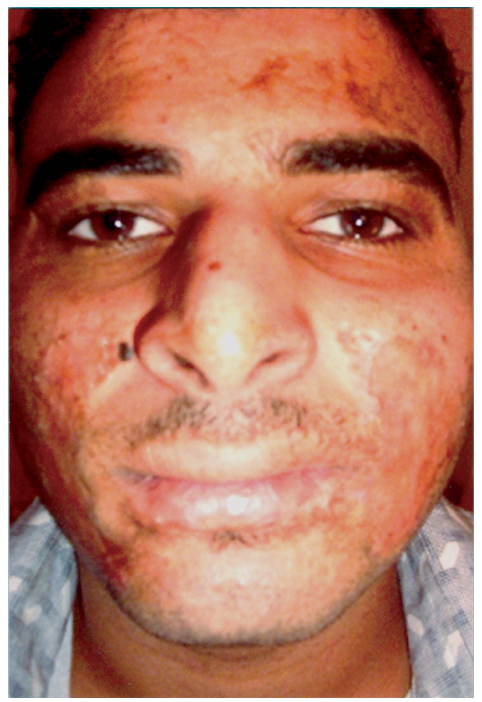

Fig. (1-B): Treated by fractional Er: YAG laser change of vascularity \& pigmentation.

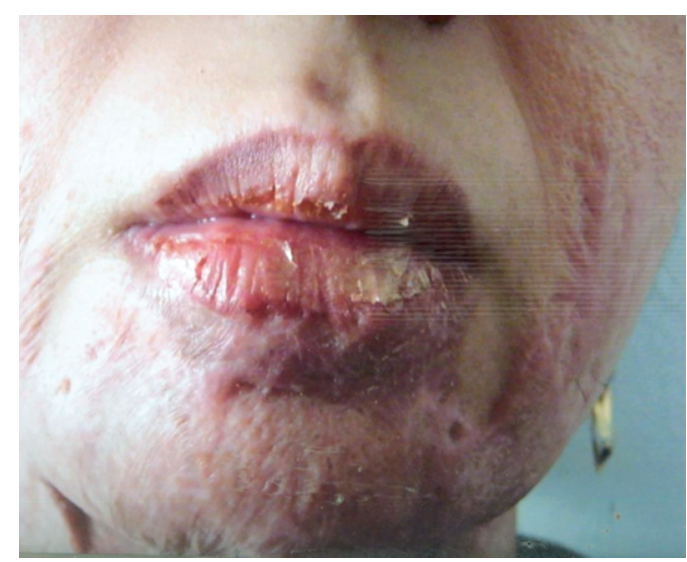

Fig. (2-B): Treated by ablative Er: YAG laser change of pigmentation \& pliability.

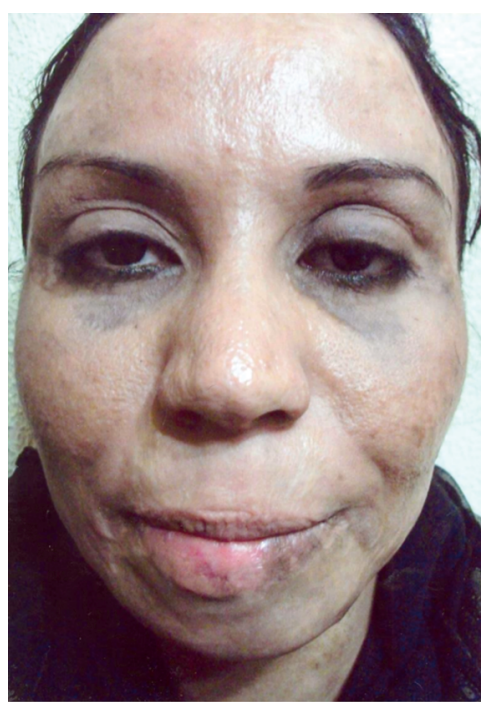

Fig. (3-B): Lip treated by ablative Er: YAG laser change of pigmentation \& vascularity. 


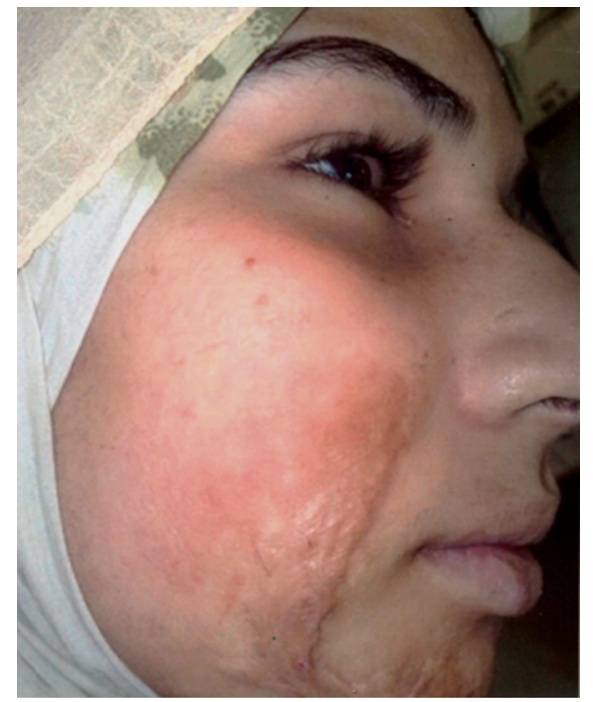

Fig. (4-A): Female pt 32ys old with post burn scar in Rt check.

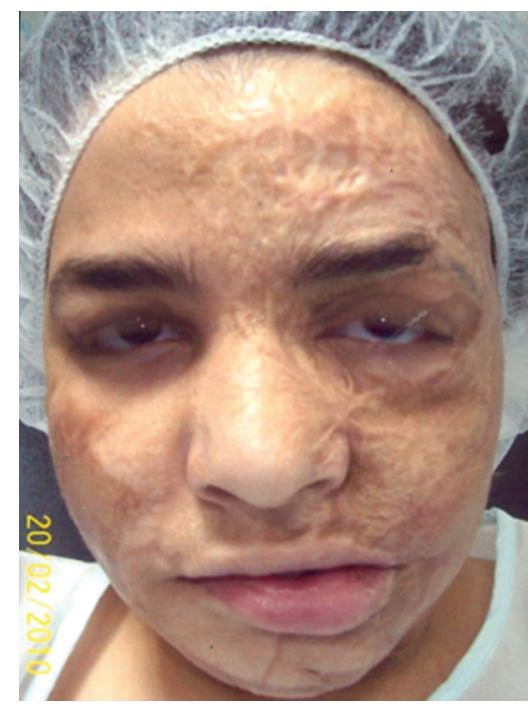

Fig. (5-A): Male pt 10ys old with post burn scar in cheek, neck \& forehead.

(A)

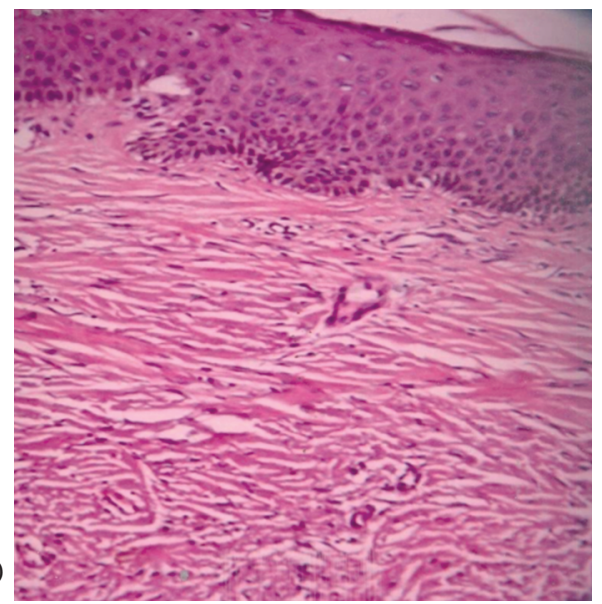

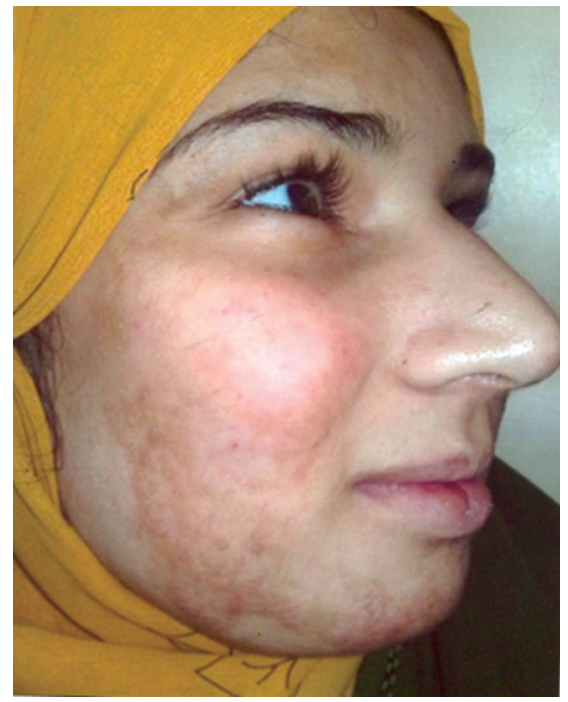

Fig. (4-B): Treated by ablative Er: YAG laser change of height \& pliability.

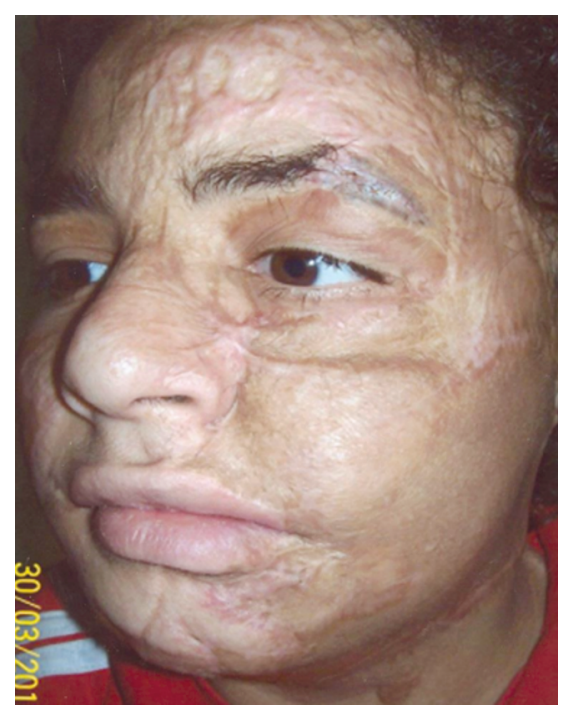

Fig. (5-B): Treated by skin graft \& followed by fractional Er: YAG laser.

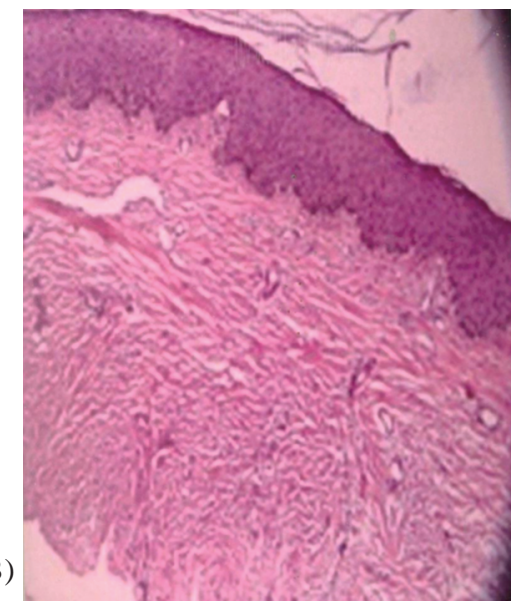

Fig. (6): Pre- and post-ablative laser histopathological findings by H\&E stain: Post burn biopsy by H\&E x 200 show epidermal hyperplasia hyperkeratosis, flat ridges and papilomatosis; ablative Er-YAG laser by H\&E x 200 show decrease thickness with flat rete ridge in epidermis. 
(A)

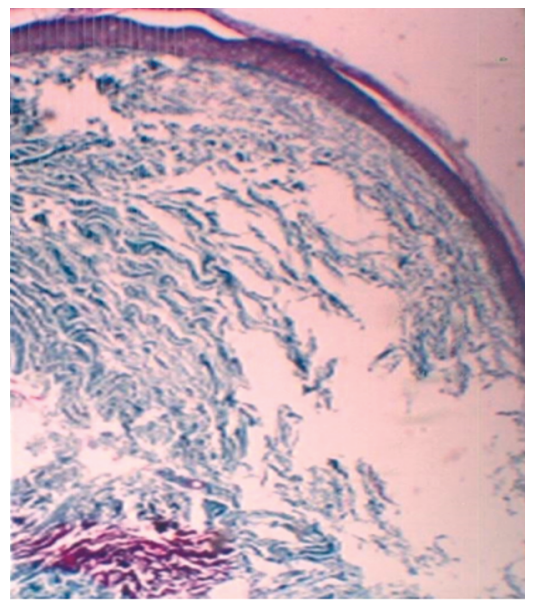

(B)

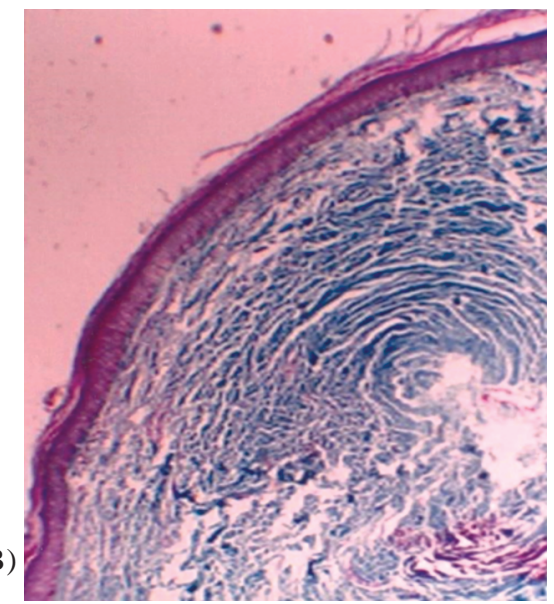

Fig. (7): Pre- and post-ablative laser histopathological findings by Masson's Trichrome stain: x 200 show epidermal hyperplasia, hyperkeratosis and papilomatosis; ablative Er-YAG laser by masson's trichrom x 200 show decrease thickness with flat rate ridges.

\section{DISCUSSION}

Conventional treatment of post burn scar was surgical but it is one of the most difficult challenges facing reconstructive surgeons, and improving the shape of cicatrix itself becomes a good option. Dermabrasion was firstly used; however, despite many case reports in literature, it is unclear if the carbon dioxide laser or the Erbium laser alone provides a long-term significant improvement. More recently, fractionated resurfacing both non ablative and ablative have been shown to have some effect on subsets of burn scars [16].

In this study, the clinical efficacy of Er: YAG laser in the treatment of post burn scars was investigated. This was found to provide highly controlled ablation with only minimal thermal necrosis, even after multiple passes [17]. In post burn scars, adnexal structures are usually destroyed and spontaneous healing can arise from the surrounding healthy skin that may results in delayed wound healing, while $\mathrm{CO}_{2}$ lasers seem to be more effective for smoothing scars it goes along with delayed healing time depending on the wound size [18]. We consider the Erbium: YAG laser to be more suitable for the treatment of scars due to lesser thermal necrosis [19].

Fractional Er: YAG laser offers a significant increase in depth of treatment and at the same time, enlarges safety margin due to substantial volume of tissue remaining intact [20]. In this study, patients with burn hypertrophic scars were selected for treatment with Er: YAG laser and assessed using VSS where the following parameters were assessed each one alone and for the total score (vascularity, pliability, pigmentation and height). Er: YAG laser generates improvements in post burn scarring as VSS assessments indicated that for about 6-11 treatments performed, on average, 24.5 days apart resulted in clinically and statistically significant improvement. These results were in accordance to results from previous studies clinical improvement was seen in all profile treatments of larger areas in the face, neck, lower neckline and hands showed improvement and they concluded, that Erbium: YAG laser to be a valuable supplementary tool for the improvement of cosmetically disturbing mild post burn hypertrophic scars [21].

The percentage of subjects with skin types IV included in this study is limited due to pigmentation concerns.

Even with the use of hydroquinone pre- and post-treatment, a recently published prospective study of 15 subjects with skin types IV-VI and acne scarring using Er: YAG laser showed [22].

The results of the present and previous studies highlight several important issues as the duration of the postoperative recovery and incidence of prolonged erythema may be lower with Er: YAG laser skin resurfacing than with $\mathrm{CO}_{2}$ laser resurfacing, also transient post inflammatory hyperpigmentation is common and may last significantly longer for the ablative hand piece than that seen after fractional Er: YAG laser; however, it may not be as persistent as that experienced after $\mathrm{CO}_{2}$ laser resurfacing. Areas with hypopigmentation showed no response to treatment Last, the average clinical improvement seen following fractional Er: YAG laser treatment for burn scars is slightly less that seen after ablative Er: YAG laser and less than $\mathrm{CO}_{2}$ laser. 


\section{REFERENCES}

1- Ozyurt K., Colgecen E., Baykan H., Oztmk P. and Ozkose M.: Treatment of superficial cutaneous vascular lesions: Experience with the long-pulsed 1064 run Nd: YAG laser. The Scientific World Journal, 2012.

2- Bock O., Schmid-Ott G., Malewski P. and Miowietz U.: Quality of life of patients with keloid and hypertrophic scarring. Arch. Dermatol. Res., 297: 433-438, 2006.

3- Van loey N.E. and Van Son M.J.: Psychopathology and psychological problems in patients with burn scars: Epidemiology and management Am. Clin. Dermatol., 4: 245272,2003

4- Berman B., Viera M.H., Amini S., Huo R. and Jones I.S.: Prevention and management of hypertrophic scars and keloids after bums in children. J. Craniofac. Surg., 19: 989-1006, 2008.

5- Hultman C.S., Edkins R.E., Lee C.N., Calvert C.T. and Caims B.A.: Shine on: Review of laser- and light-based therapies for the treatment of bum scars. Dermatology Research and Practice, 2012.

6- Alster T.S. and Tanzi E.L.: Hypertrophic scars and keloids: Etiology and management. Am. J. Clin. Dermatol., 4: 235-243, 2003.

7- Tavares Biho J.M., Belerique M., Franco D., Porchat C.A. and Franco T.: Tissue expansion in bum sequelae repair. Bums, 33: 246-251, 2007

8- Parrett B.M. and Demelan M.B.: Pulsed dye laser in burn scare: Current concepts and future directions. Bums, 36: 443-449, 2010.

9- Hffideersdal M., Moreau K.E., Beyer D.M., Nymann P. and Alsbjom B.: Fractional uonablative 1540nm laser resurfacing for thermal bum scars: A randomized controlled trial. Lasers Surg. Med., 41: 189-195, 2009.

10- Vrijman C., Van Drooge A.M., Limpens J., Bos J.D., Van Der Veen J.P., et al.: Laser and intense pulsed light therapy for the treatment of hypertrophic scars: A systematic review. Br. J. Dermatol., 165: 934-942, 2011.

11- Bouzari N., Davis S.C. and Nouri K.: Laser treatment of keloids and hypertrophic scars. Int. J. Dermatol., 46: 8088, 2007.

12- Thomas J.R. and Somenek M.: Scar revision review. Archives of facial plastic surgery, 14: 162-174, 2012.

13- Majaron B., Srinivas S.M., Huang H.E. and Nelson J.S.: Deep coagulation of dermal collagen with repetitive Er: YAG laser irradiation. Lasers Surg. Med., 26: 215-222, 2000.

14- Nouri K., Vkiulich K. and Rivas M.P.: Lasers for scars A review. J. Cosmet. Dermatol., 5: 14-22, 2006.

15- Saryazdi S. and Mohebbi A.: Evaluation of fractional CO2 laser efficacy in acne scar. J. Lasers Med. SD, 3: $56,2012$.

16- Tanzi E.L. and Alster T.S.: Treatment of atrophic facial acne scars with a Dual-Mode En YAG laser. Dennatol. Surg., 28: 551-555, 2002.

17- Gladstone H.B., Berg D. and McDonald M.: Scar revision. Dennatol. Res. Pract., 2010.

18- Weinstein C.: Computerized scanning Erbiumi: YAG laser for skin resurfacing. Dermatol. Surg., 24: 83-89, 1998.

19- Kwon S.D. and Kye Y.C.: Treatment of scars with a pulsed Er: YAG laser. Cutan Laser Ther., 2: 27-31, 2000.

20- Waibel J., Graber E., Davis S. and Badiavas E.: Effects of erbium fractional resurfacing on third degree hypertrophic bum scars. Lasers in Surgery and Medicine, 44: 11-11, 2012.

21- Dierickx C., Khatri K., Altshuler G., Erofeev A., Smimov M., et al.: Fractionated delivery of Er: YAG laser light to improve efficacy and safety of ablative resurfacing procedure. Lasers Surg. Med., 2007.

22- Eberiein A., Schepler H., Spilker G., Altmeyer P. and Hartmann B.: Erbium: YAG laser treatment of post-burn scars: Potentials and limitations. Bums, 31: 15-24, 2005.

23- Mahmoud B.H., Srivastava D., Janiga J.J., Yang J.J., Lim H.W., et al.: Safety and efficacy of erbium-doped yttrium aluminum garnet fractionated laser for treatment of acne scars in type IV to VI skin. Dermatol. Surg., 36: 602-9, 2010.

24- Manuskiatti W., Lamphonrat T.W. and Nitphakdeedecha R., Eimpunth S.: Comparison of fractional erbium-doped yttrium acne scars in Asians. Dermatol. Surg., 39: 111$20,2013$.

25- W. James Tidwell, M.D.1, Cindy E. Owen, M.D.1, Carol Kulp-Shorten, M.D.1, Abhishek Maity, B.A.2, Michael McCall M.D.1 and Timothy S. Brown, M.D.: Fractionated Er: YAG laser versus fully ablative Er: YAG laser for sar revision: Results of a split scar, double binded, prospective trial, 37: 501-7.

26- Jang J-U., Kim S-Y., Yoon E-S., et al.: Comparison of the effectiveness of ablative and non-ablative fractional laser treatments for early stage thyroidectomy scars. Arachives of Plastic Surgery, 43 (6): 575-581, 2016. doi:10.5999/ aps.2016.43.6.575

27- Tanzi E.L. and Alster T.S.: Comparison of a 1450-nm diode laser and a 1320-nm Nd: YAG laser in the treatment of atrophic facil scars: A prospective clinical and histologic study. Dermatol. Surg., 30: 152-157, 2004.

28- Borges J., Cuzzi T., Mandarim-de-Lacerda C.A. and Manela-Azulay M.: An Bras Dermatol. Mar-Apr., 89 (2): 250-8, 2014.

29- Alexiades-Armenakas M.R., Dover J.S. and Arndt K.A.: J. Am. Acad. Dermatol., May, 58 (5): 719-37; quiz 73840, 2008.

30- Preissig J., Hamilton K. and Markus R.: Current laser resurfacing technologies: A review that delves beneath the urface. Seminars in plastic surgery, 26 (3): 109-116, 2012. http://doi.org/10.1055/s-0032-1329413. 